\title{
Preventive effects of Chlorella on skeletal muscle atrophy in muscle-specific mitochondrial aldehyde dehydrogenase 2 activity-deficient mice
}

Yuya Nakashima ${ }^{1,2^{*}}$, Ikuroh Ohsawa ${ }^{3}$, Kiyomi Nishimaki², Shoichiro Kumamoto ${ }^{1}$, Isao Maruyama', Yoshihiko Suzuki ${ }^{2}$ and Shigeo Ohta ${ }^{2}$

\begin{abstract}
Background: Oxidative stress is involved in age-related muscle atrophy, such as sarcopenia. Since Chlorella, a unicellular green alga, contains various antioxidant substances, we used a mouse model of enhanced oxidative stress to investigate whether Chlorella could prevent muscle atrophy.

Methods: Aldehyde dehydrogenase $2(\mathrm{ALDH} 2)$ is an anti-oxidative enzyme that detoxifies reactive aldehydes derived from lipid peroxides such as 4-hydroxy-2-nonenal (4-HNE). We therefore used transgenic mice expressing a dominantnegative form of $\mathrm{ALDH} 2$ ( $\mathrm{ALDH} 2^{*} 2 \mathrm{Tg}$ mice) to selectively decrease ALDH2 activity in the muscles. To evaluate the effect of Chlorella, the mice were fed a Chlorella-supplemented diet (CSD) for 6 months.

Results: ALDH2*2 Tg mice exhibited small body size, muscle atrophy, decreased fat content, osteopenia, and kyphosis, accompanied by increased muscular 4-HNE levels. The CSD helped in recovery of body weight, enhanced oxidative stress, and increased levels of a muscle impairment marker, creatine phosphokinase (CPK) induced by ALDH2*2. Furthermore, histological and histochemical analyses revealed that the consumption of the CSD improved skeletal muscle atrophy and the activity of the mitochondrial cytochrome c oxidase.

Conclusions: This study suggests that long-term consumption of Chlorella has the potential to prevent age-related muscle atrophy.
\end{abstract}

Keywords: Muscle atrophy, Chlorella, Aldehyde dehydrogenase 2, Mitochondrial cytochrome c oxidase, Oxidative stress

\section{Background}

Excessive production of reactive oxygen species (ROS) causes oxidative damage to DNA, proteins, and lipids. This damage accumulates with age in various organs, including the skeletal muscle, as observed in both humans [1-4] and animal models [5,6]. Thus, it is hypothesized that some antioxidants may aid in preventing agerelated disorders, including muscle atrophy, such as sarcopenia.

We have sought to develop animal models with enhanced oxidative stress and various impairments that are

\footnotetext{
* Correspondence: yuya_nakashima@chlorella.co.jp

'Department of Research and Development, Chlorella Industry Co. Ltd, 1343 Hisatomi, Chikugo, Fukuoka 833-0056, Japan

${ }^{2}$ Department of Biochemistry and Cell Biology, Institute of Development and Aging Sciences, Nippon Medical School, 1-396 Kosugi-machi, Nakahara-ku, Kawasaki, Kanagawa 211-8533, Japan

Full list of author information is available at the end of the article
}

affected by age $[7,8]$. Aldehyde dehydrogenases (ALDH) catalyze the conversion of reactive aldehydes to carboxylates [9]. Mitochondrial ALDH2 is known to oxidize acetaldehyde produced from ethanol into acetate [10], and a single nucleotide polymorphism in this gene found in Asian populations, $A L D H 2 * 2$, produces a dominantnegative protein that prevents this activity. We have previously revealed, through a molecular epidemiological analysis, that a higher concentration of lipid peroxides are present in the sera of ALDH2-deficient females than in those expressing active ALDH2 [11]. Furthermore, we demonstrated that ALDH2 deficiency is a risk factor for late-onset Alzheimer's disease [12], suggesting a role for this polymorphism in human diseases. Recently, ALDHs have emerged as an important enzyme in a variety of human pathologies. ALDH2 dysfunction contributes to a variety of human diseases including diabetes, cancer, 
cardiovascular diseases [13-15], neurodegenerative diseases, stroke, Fanconi anemia, pain, osteoporosis, and the aging process [16].

In previous examinations of $\mathrm{ALDH} 2 * 2$, we showed that mitochondrial ALDH activity was repressed when murine ALDH2 2 was stably expressed in the neuronal cell line PC12. Cells expressing ALDH2*2 were also vulnerable to 4-hydroxy-2-nonenal (4-HNE), and treatment with 4-HNE or antimycin A was shown to induce cell death $[17,18]$. Additionally, ALDH deficiency enhanced oxidative stress through a vicious cycle [8].

A Tg mouse model expressing ALDH2*2 specifically in the brain decreased the ability of mice to detoxify 4HNE in cortical neurons and accelerated the accumulation of 4-HNE in the brain [7]. Consequently, these mice presented with age-related neurodegeneration accompanied by memory loss after maturation. Mice deficient in muscle-specific mitochondrial ALDH2 activity were also developed by inducing the transgenic expression of ALDH2*2 under the control of the actin promoter [8]. These model animals will be helpful in investigating the antioxidant properties of health foods in vivo, as well as in studies examining the prevention of oxidative stressrelated muscle atrophy.

Sarcopenia is the decline of muscle mass and strength that occurs with aging [19]. Since the progression of sarcopenia induces significant physical depression [20-22], this condition increases the risk of fractures due to fall and the possibility of becoming bedridden in elderly people. A central mechanism in the pathogenesis of sarcopenia is oxidative stress [23], which has been detected by the accumulation of several oxidative stress markers. These aldehyde species, which primarily include malondialdehyde (MDA) and 4-HNE, are spontaneously generated from lipid peroxides [24]. Interestingly, 4-HNE is a strong electrophile that rapidly reacts with most biomolecules [25].

Chlorella, a unicellular green alga, contains a variety of nutritional components that are rich in protein, fatty acids, dietary fiber, chlorophylls, minerals, vitamins, and carotenoids. Thus, dried Chlorella powder or extracts in hot water have long been used as a health supplement in Asia. It has been reported that Chlorella elicits various immunopharmacological effects [26-28] and functions as an antioxidant in vitro and in vivo [29-37]. This is likely because it is rich in carotenoids and other antioxidants, including lutein, $\beta$-carotene, $\alpha$-tocopherol, and ascorbic acid. We have already demonstrated that long-term consumption of Chlorella did not significantly affect the weight of any organs in wild type rats [38], and that long-term Chlorella consumption prevents oxidative stress, age-dependent cognitive decline, and central nervous system disorders in $\mathrm{Tg}$ mice expressing $\mathrm{ALDH} 2 * 2$ in the brain [39]. Thus, Chlorella supplements have displayed antioxidant effects in a variety of animal experiments. However, it is unknown whether the consumption of Chlorella has an antioxidant effect in muscle tissues. Importantly, inflammation may cause sarcopenia in addition to oxidative stress. Since Chlorella extract slight decreased the expression of the pro-inflammatory cytokine IL-6 in mice [40], we here focused on the effects of oxidative stress.

In this study, we fed Chlorella to mice expressing a dominant negative, muscle-specific form of mitochondrial ALDH2 for 6 months. Our findings suggest that this supplement has the potential to mitigating skeletal muscle atrophy.

\section{Methods}

\section{Animals and treatment}

Tg mice expressing ALDH2*2 in the skeletal muscle were previously reported [8]. Heterozygous male mice were mated with female C57BL/6 mice (Kyudo, Fukuoka, Japan). Genotyping of the resulting mice was performed by PCR using genomic DNA isolated from the tail tip and 2 sets of combinatorial primers (5'-CGTGCTGGTTATT GTGCTGTCTCA-3' and 5'-GAAGGGTTGACGGTGG GAAATGTT-3'; 5' -TGGCGTGGTCAATATCGTTCCC$3^{\prime}$ and 5'-GAGCTTGGGACAGGTAATTGGC-3') in order to amplify the exogenous ALDH2*2 gene. Sixteen heterozygous ALDH2*2 Tg male mice were identified and used in the experiments described in this report. These mice were divided into 2 groups of 8 mice at 8 weeks of age. By this time, the two groups had developed a uniform average of body weight. One group was fed a basic diet (Control group), while the other group was fed a $1 \%$ Chlorella-supplemented diet (CSD group) for 6 months. The experimental dietary compositions were based on the AIN-93 M [41], and are shown in Table 1. Wild type littermates were also fed the basic diet. All animals were kept on a $12 \mathrm{~h}$ light/dark cycle with ad libitum access to water and food throughout the experimental period, and body weight and food intake were measured at the end of each month. This study was approved by the Animal Care and Use Committee of Chlorella Industry Co., Ltd., according to the National Institutes of Health published guidelines.

\section{Chlorella powder}

The Chlorella powder used to prepare the CSD was from the Parachlorella beijerinckii CK-5 strain, and was cultured, dried, and powdered by Chlorella Industry Co., Ltd. The general characteristics and composition of the Chlorella powder is shown in Table 2.

\section{Sample collection}

All mice were anesthetized and sacrificed prior to blood sample collection from the hepatic portal vein. Plasma was subsequently obtained by centrifugation at $3000 \times g$ 


\begin{tabular}{|c|c|c|}
\hline Ingredients & $\begin{array}{c}\text { Control and } \\
\text { wild type groups }\end{array}$ & CSD group \\
\hline Casein & 140.0 & 138.6 \\
\hline L-Cysteine & 1.8 & 1.8 \\
\hline Corn starch & 465.7 & 460.5 \\
\hline Dextrinized corn starch & 155.0 & 153.5 \\
\hline Sucrose & 100.0 & 99.0 \\
\hline Soybean oil & 40.0 & 39.6 \\
\hline Fiber & 50.0 & 49.5 \\
\hline Vitamin mix (AIN-93-VM) ${ }^{a}$ & 10.0 & 10.0 \\
\hline Mineral mix (AIN-93-MX) & 35.0 & 35.0 \\
\hline Choline bitartrate & 2.5 & 2.5 \\
\hline Tert-butylhydroquinone & 0.008 & 0.008 \\
\hline Chlorella powder & 0 & 10.0 \\
\hline Total weight (g) & 1000 & 1000 \\
\hline Energy (kJ) & 16362 & 16358 \\
\hline
\end{tabular}

Quantity expressed as $\mathrm{g} / \mathrm{kg}$ diet.

Control ALDH2*2 mice were fed a basal diet, CSD ALDH2*2 mice a Chlorella-

supplemented diet, and Wild type C57BL6 mice basal diet.

atitamins and minerals based on AIN-93 M formulation [41].

for $15 \mathrm{~min}$ at $4^{\circ} \mathrm{C}$. The liver, kidneys, heart, lung, spleen, right gastrocnemius muscle, and adipose tissue (epididymal) of each mouse were quickly excised and weighed. For histological and histochemical studies, the left gastrocnemius muscle was frozen in hexane with Optimal Cutting Temperature (OCT) Compound (Sakura Finetek Japan, Tokyo, Japan) at $-80^{\circ} \mathrm{C}$. The quadricep muscle was washed with cold phosphate buffered saline $(\mathrm{pH} 7.4)$ and frozen in liquid nitrogen. All samples were stored at $-80^{\circ} \mathrm{C}$ until use.

\section{Plasma analysis}

The plasma activities of creatine phosphokinase (CPK) and creatine phosphokinase-MB (CKMB) were measured

Table 2 Chlorella powder composition

\begin{tabular}{lc}
\hline Component & Chlorella powder (per $\mathbf{1 0 0}$ g powder) \\
\hline Protein & $65 \mathrm{~g}$ \\
Carbohydrate & $0.9 \mathrm{~g}$ \\
Fat & $11.9 \mathrm{~g}$ \\
Dietary Fiber & $10.2 \mathrm{~g}$ \\
Ash & $6.6 \mathrm{~g}$ \\
Moisture & $5.4 \mathrm{~g}$ \\
Lutein & $274 \mathrm{mg}$ \\
a-Carotene & $12 \mathrm{mg}$ \\
$\beta$-Carotene & $118 \mathrm{mg}$ \\
Ascorbic acid & $46 \mathrm{mg}$ \\
a-Tocopherol & $32.8 \mathrm{mg}$ \\
\hline
\end{tabular}

using a DRI-CHEM autoanalyzer (FUJIFILM, Tokyo, Japan).

\section{Bone density measurement}

For computed tomography analysis of bone density, the whole bodies of the mice were scanned using a LaTheta LCT-100 experimental animal computed tomography system (Aloka, Tokyo, Japan). Contiguous 1-mm thick slices were used for quantitative assessment using LaTheta software (ver 1.00). Bone density was evaluated quantitatively.

\section{Analysis of urinary oxidative stress}

In order to measure urinary oxidative stress markers, mice were placed in a urine-sampling cage for $12 \mathrm{~h}$ at 2 and 4 months after the experiment began, and urine was collected. Urinary isoprostane levels were determined using a urinary isoprostane $\mathrm{F}_{2 \mathrm{t}}$ ELISA kit (JaICA, Fukuroi, Japan), according to the manufacturer's instructions. The creatinine concentration of each sample was measured using a LabAssay Creatinine kit (Wako, Osaka, Japan). Urinary isoprostane levels were normalized against creatinine concentration.

\section{Measurement of oxidative stress in skeletal muscle}

MDA and 4-hydroxyalkenals (HAE) levels in the quadriceps muscles were determined using a Bioxytech LPO-586 assay kit (OxisResearch, Oregon, USA). Briefly, pieces of the quadriceps muscle were homogenized in phosphatebuffered saline ( $\mathrm{pH}$ 7.4) containing $5 \mathrm{mM}$ butylated hydroxytoluene. After homogenization, the samples were centrifuged at $3000 \times g$ for $10 \mathrm{~min}$ at $4^{\circ} \mathrm{C}$, and the clear supernatants were subjected to the LPO-586 assay. MDA and HAE levels were assayed using the methanesulfonic acid solvent procedure according to the manufacturer's instructions. The LPO-586 assay is based on the reaction of a chromogenic reagent, $N$-methyl-2-phenylindole, with $\mathrm{MDA}$ and $\mathrm{HAE}$ at $45^{\circ} \mathrm{C}$. These compounds react with $N$ methyl-2-phenylindole to yield a stable chromophore with a maximal absorbance at $586 \mathrm{~nm}$. The absorbance of the resultant samples was measured at $586 \mathrm{~nm}$. The protein concentration of each sample was measured using a Pierce BCA protein assay kit (Thermo Scientific, Rockford, USA). MDA and HAE levels were normalized against protein concentration.

\section{Histological and histochemical studies}

Frozen gastrocnemius muscle samples were sliced into sections (8- $\mu \mathrm{m}$ thick) and mounted on silane-coated glass slides. Frozen sections were dried and stained with hematoxylin and eosin (H\&E). For enzymatic cytochrome $c$ oxidase histochemical staining, frozen sections were dried and incubated in $0.1 \mathrm{~mol} / \mathrm{L}$ sodium phosphate ( $\mathrm{pH} 7.4), 0.5 \mathrm{mg} / \mathrm{ml} \mathrm{3,3-diaminobenzidin} \mathrm{(DAB,}$ 
Wako), $130 \mu \mathrm{g} / \mathrm{ml}$ catalase (Nacalai tesque, Kyoto, Japan), and $1 \mathrm{mg} / \mathrm{ml}$ cytochrome $c$ (Nacalai tesque) at room temperature for $60 \mathrm{~min}$. The cross-sectional area of the gastrocnemius muscle cells and the area of stained cytochrome $c$ oxidase were calculated using the Image J (ver1.41; National Institutes of Health, Bethesda, MD), and they are presented as the percent ratio (\%) versus wild type from 3 different points for each mouse.

\section{Statistical analysis}

All values shown are the mean \pm SD. One-way ANOVA (Fisher's PLSD test) followed by contrast testing was used to compare the data from multiple groups. Relationships between given variables were examined by linear regression analysis and the Pearson correlation coefficient. All experiments were examined in a blinded fashion, and statistical significance was accepted as $p<0.05$.

\section{Results}

Consumption of a Chlorella-supplemented diet reduces oxidative stress and reverses skeletal muscle impairment To investigate oxidative stress in the ALDH $2 * 2 \mathrm{Tg}$ mice, we examined the levels of the urinary oxidative stress marker isoprostane, 2 and 4 months after initiating CSD feeding. Although no difference was observed between the CSD and Control groups after 2 months, the level of urinary isoprostane was decreased in mice fed the CSD for 4 months (Figure 1a). In addition, we measured a second oxidative stress marker, MDA and HAE, in quadriceps muscle after 6 months of Chlorella consumption, and found that the accumulation of the oxidative stress marker was notably suppressed in these mice (Figure 1b).

Excess oxidative stress is known to impair muscle. To evaluate the extent of muscle impairment in the ALDH2*2 Tg mice, we measured the levels of CPK and CKMB expression in plasma. The ALDH2*2 Tg mice had increased

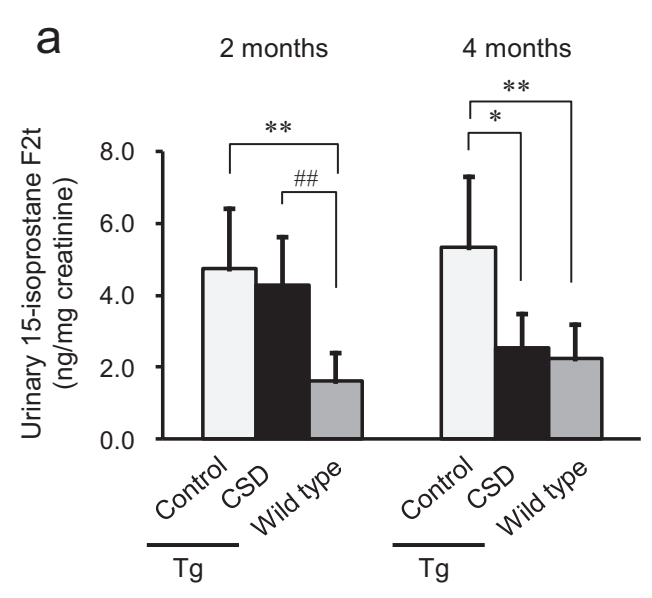

C

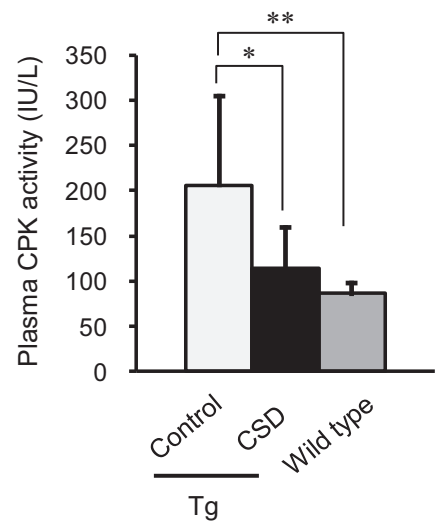

b

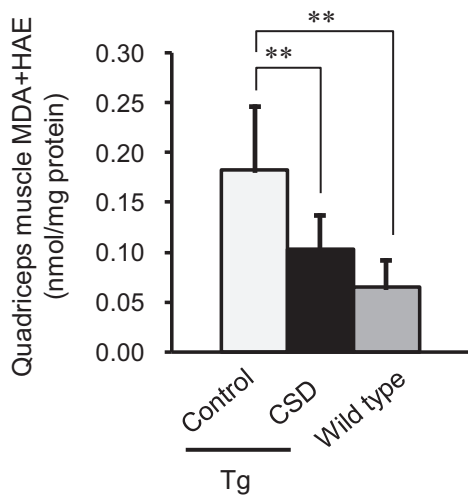

d

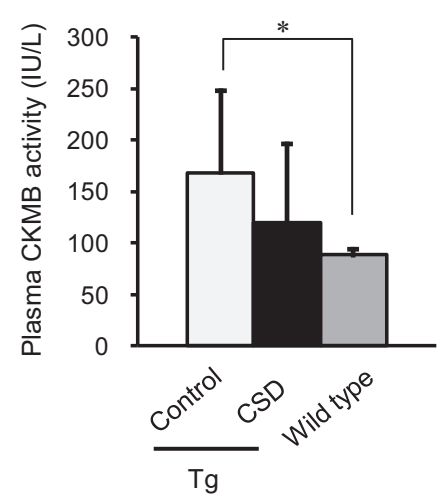

Figure 1 Consumption of Chlorella reduced oxidative stress and muscle tissue injury in ALDH2*2 Tg mice. Wild type $(n=7)$ and control ALDH2*2 Tg mice $(n=8)$ were fed a basal diet, while the CSD ALDH2*2 Tg mice received a Chlorella-supplemented diet $(n=8)$. Urinary 15-isoprostane levels were measured 2 and 4 months after the initial Chlorella administration (a). After 6 months of consuming the Chlorella diet, MDA and HAE were measured in the quadriceps muscle (b). The levels of CPK (c) and CKMB (d) detectable in plasma were measured 6 months after initial Chlorella administration. Values are the mean \pm SD, ${ }^{*} p<0.05$ and ${ }^{* *} p<0.01$ : significant vs. Control; ${ }^{*} p<0.01$ : significant vs. Wild type. 
levels of both proteins; however, CPK levels were significantly reduced after CSD administration (Figure 1c). A trend toward reduced of CKMB levels was also observed (Figure 1d). These results suggest that the consumption of Chlorella reduces oxidative stress and reverses skeletal muscle impairment in ALDH2*2 mice (Figure 1).

\section{Effect of Chlorella-supplemented diet consumption on body size and skeletal muscle atrophy}

One month following the initiation of the experimental diets, wild type mice were observed to have a significantly increased body weight compared to ALDH2*2 Tg mice (Figure 2a), suggesting that muscle-specific ALDH2 deficiency has a negative impact on body size. Compared to the consumption of a basic diet, CSD consumption for 4 months resulted in a greater body size in the ALDH2*2 Tg mice (Figure 2a). Importantly, no differences in food intake among any of the groups were observed (Figure 2b), indicating that the body weight of the mice in the CSD group was restored in a food intake-independent manner.

The weight of the organs and bone density of the experimental mice were also measured after 6 months of consuming the respective diets. The weights of both the gastrocnemius muscles and epididymal fat of the CSD group were significantly heavier than those of the Control group (Table 3). In addition, the CSD appeared to suppress the decline in bone density observed in the Control group (Table 3). These results suggest that the consumption of Chlorella is beneficial for the growth of ALDH2*2 Tg mice.

To examine the effects of CSD consumption on muscle atrophy, we measured the cross-sectional area of the gastrocnemius muscle cells in our experimental mice using H\&E staining. The ALDH2*2 Tg mice exhibited a significantly higher cross-sectional area of gastrocnemius muscle cells after consuming the CSD for 6 months than the control mice (Figure $3 \mathrm{a}-\mathrm{d}$ ), suggesting that consumption of Chlorella improved skeletal muscle atrophy. Furthermore, when the correlation between oxidative stress in quadriceps and gastrocnemius muscle atrophy was examined, we found that the relative cross-sectional areas of the gastrocnemius muscle cells were negatively correlated with the expression level of MDA and HAE $(\mathrm{r}=-0.58, p<0.01$, Figure 3e).

\section{Protective effects of Chlorella-supplemented diet consumption on mitochondrial dysfunction in ALDH2*2 Tg mice}

To investigate mitochondrial function in skeletal muscle, we measured cytochrome $c$ oxidase activity in the gastrocnemius muscle. When enzymatic histochemical staining for cytochrome $c$ oxidase was performed, it was found that notable cytochrome $c$ oxidase activity decline was detectable in the gastrocnemius muscle of the ALDH2 $2 \mathrm{Tg}$ Control group, while it was significantly decreased in the CSD group (Figure $4 \mathrm{a}-\mathrm{d}$ ). This suggests that Chlorella consumption prevented mitochondrial dysfunction in gastrocnemius muscle. In addition, the relative level of cytochrome $c$ oxidase activity was negatively correlated with the levels of MDA and $\operatorname{HAE}(\mathrm{r}=-0.74, p<0.001$, Figure 4e).

\section{Discussion}

The present study demonstrated that long-term intake of Chlorella reduced oxidative stress, as determined by changes in oxidative stress markers, including urinary 15-isoprostane and muscle MDA and HAE in transgenic mice with enhanced oxidative stress. This improvement resulted in decreased disintegration of muscle, plasma
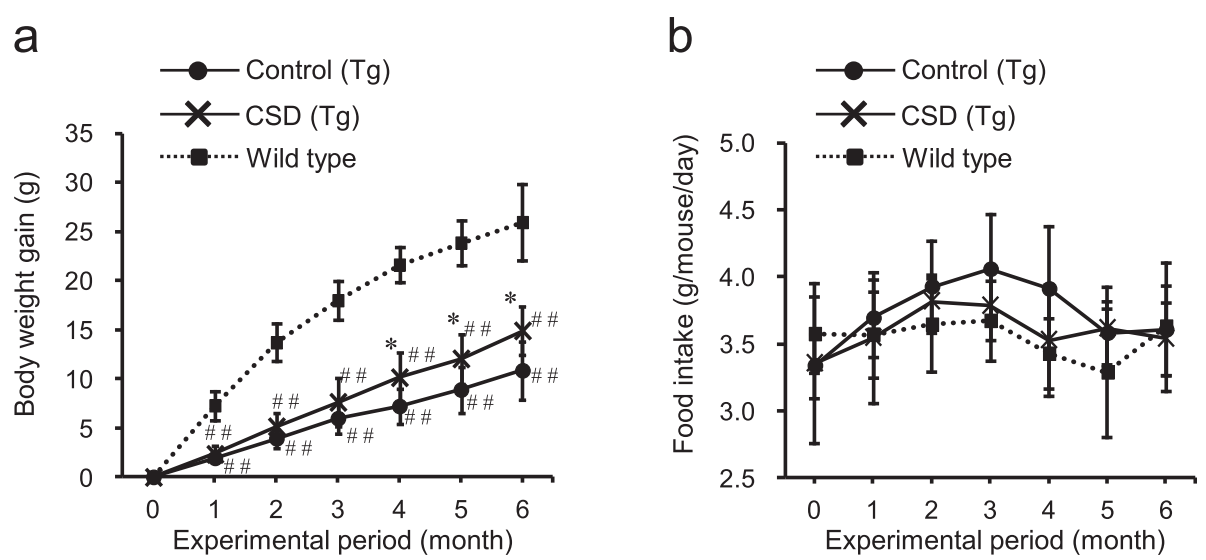

Figure 2 Effects of Chlorella consumption on body weight gain and food intake. All groups were fed the respective diets shown in Table 1 , beginning at 2 months of age. Wild type $(n=7)$ and control ALDH2*2 Tg mice were fed a basal diet $(n=8)$, while the CSD ALDH2*2 Tg mice received a Chlorella-supplemented diet $(n=8)$. Body weights $(\mathbf{a})$ and food intake $(\mathbf{b})$ were measured at the end of each month. Values are the mean \pm SD, ${ }^{*} p<0.05$ : significant vs. Control; ${ }^{\#} p<0.01$ : significant vs. Wild type. 
Table 3 Effects of Chlorella consumption on bone density and organ weights

\begin{tabular}{|c|c|c|c|}
\hline & $\mathrm{ALDH}_{2}$ & $2 * 2 \mathrm{Tg}$ & \\
\hline & $\begin{array}{c}\text { Control } \\
\text { group }\end{array}$ & CSD group & $\begin{array}{l}\text { Wild type } \\
\text { group }\end{array}$ \\
\hline $\begin{array}{l}\text { Bone density } \\
\left(\mathrm{mg} / \mathrm{cm}^{3}\right)\end{array}$ & $410.9 \pm 24.0^{\#}$ & $426.5 \pm 21.8$ & $442.0 \pm 21.5$ \\
\hline Organ weights & & & \\
\hline Liver & $1230.5 \pm 134.6^{\# \#}$ & $1265.2 \pm 140.0^{\# \#}$ & $2082.4 \pm 391.9$ \\
\hline Kidney & $224.4 \pm 37.6$ & $238.4 \pm 25.5$ & $237.9 \pm 32.6$ \\
\hline Heart & $129.3 \pm 16.0^{\# \#}$ & $135.1 \pm 7.6^{\# \#}$ & $165.5 \pm 6.8$ \\
\hline Lung & $212.8 \pm 23.3^{\# \#}$ & $212.2 \pm 27.0^{\# \#}$ & $263.8 \pm 50.9$ \\
\hline Spleen & $54.0 \pm 6.9^{\# \#}$ & $60.5 \pm 9.4^{\# \#}$ & $80.1 \pm 11.1$ \\
\hline $\begin{array}{l}\text { Gastrocnemius } \\
\text { muscle }\end{array}$ & $107.9 \pm 10.8^{\# \#}$ & $129.8 \pm 19.6^{*, \# \#}$ & $189.0 \pm 8.4$ \\
\hline Epididymal fat & $521.7 \pm 265.3^{\# \#}$ & $824.2 \pm 144.9^{* \text {,\#\# }}$ & $1044.8 \pm 174.4$ \\
\hline
\end{tabular}

CPK, and plasma CKMB, and increased bone density, organ weight, muscle cell size, and total body weight. Moreover, mitochondrial activity was improved by longterm intake of Chlorella in the oxidative stress-enhanced mice.

Oxidative stress in skeletal muscle is associated with the atrophy, loss of muscle function, and fibers in sarcopenia $[23,42]$. Thus, it is important to reduce oxidative stress in our daily lives. Indeed, epidemiological studies of community-dwelling older adults have demonstrated that the low carotenoid level in blood is associated with low skeletal muscle strength and the development of walking disabilities [43]. These reports further indicate that dietary carotenoid intake is efficacious in the prevention age-related muscle disorders.

It is unknown why Chlorella was effective in reducing oxidative stress. As Chlorella contains various dietary antioxidant substances, including carotenoids and vitamins, it could be a potential dietary source of these compounds. Additionally, Chlorella also has a large chloroplast, in which plastoquinone substitutes for ubiquinone as an electron carrier in the photosynthetic electron-transport chain. Plastoquinone has been shown to have greater antioxidant properties than ubiquinone [44] and does not
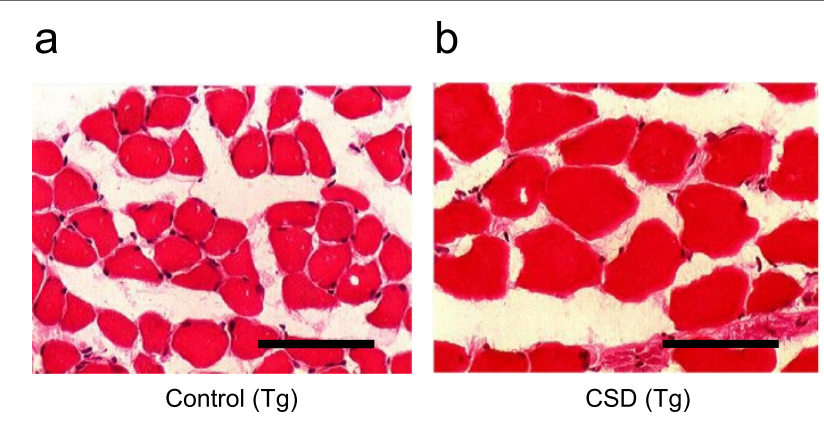

C
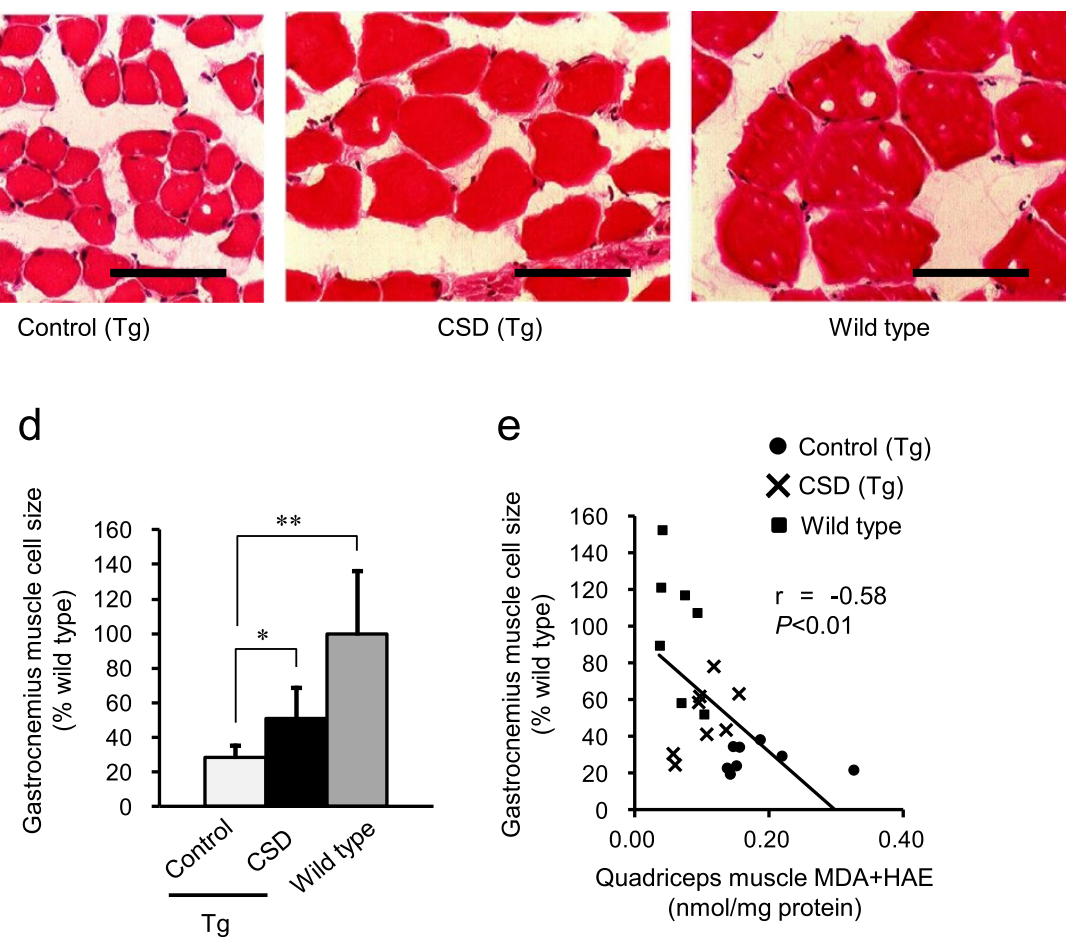

Figure 3 Chlorella consumption prevents skeletal muscle atrophy in ALDH2*2 Tg mice. The cross-sectional areas of gastrocnemius muscle cells were stained with H\&E 6 months after the initial administration of Chlorella in the diet. The scale bar indicates $100 \mu$ m (a-c). Gastrocnemius muscle cell size was measured, and is presented as the percent ratio (\%) versus Wild type (d). Gastrocnemius muscle cell size and MDA and HAE had a significant negative correlation (e). Values are the mean $\pm S D,{ }^{*} p<0.05$ and ${ }^{* *} p<0.01$ : significant vs. Control. 

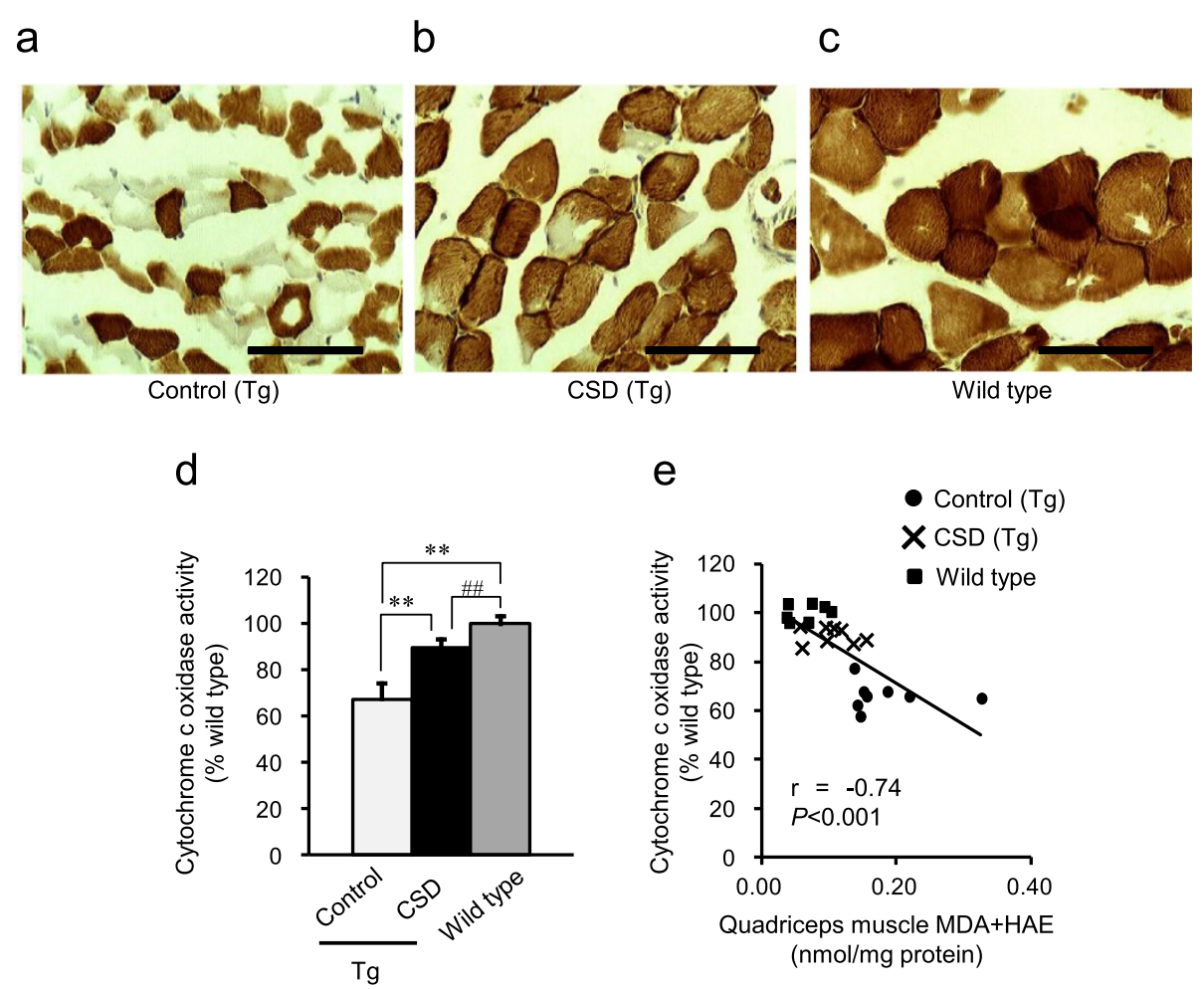

Figure 4 Effects of Chlorella consumption on mitochondrial cytochrome $c$ oxidase activity in ALDH2*2 Tg mice. Enzymatic histochemical staining for cytochrome $c$ oxidase in the mitochondria of the gastrocnemius muscle cells 6 months after the initial administration of Chlorella in the diet. The scale bar indicates $100 \mu \mathrm{m}(\mathbf{a}-\mathbf{c})$. Gastrocnemius muscle cytochrome $\mathbf{c}$ oxidase activity was measured and is presented as the percent ratio (\%) versus Wild type (d). A significant negative correlation was observed between gastrocnemius muscle cytochrome $c$ oxidase activity and MDA and HAE levels in quadriceps muscle (e). Values are the mean $\pm \mathrm{SD},{ }^{* *} p<0.01$ : significant vs. Control; ${ }^{\# \#} p<0.01$ : significant vs. Wild type.

pose a danger for pro-oxidant effects within a range of concentrations [45]. Therefore, the effect of Chlorella is likely synergistic between the plastoquinone and carotenoids provided in the CSD, thereby protecting against the impairments observed in ALDH2*2 Tg mice. Indeed, we have previously shown that Chlorella consumption reduces oxidative stress (4-HNE) in the dentate gyrus of the hippocampus [39]. In the present study, we have further demonstrated that the consumption of a CSD markedly suppresses oxidative stress in the quadriceps muscle, and that there is a negative correlation between oxidative stress in quadriceps and gastrocnemius muscle atrophy.

The age-dependent accumulation of mitochondrial DNA (mtDNA) mutations, which lead to mitochondrial dysfunction, may be an important contributor to sarcopenia $[46,47]$. A causal role for these age-related mtDNA deletion mutations and mitochondrial dysfunction in sarcopenia has been supported by findings that these alterations induce the loss of cytochrome $c$ oxidase activity in aged rats, primates, and human skeletal muscle cross sections [48-52]. Conversely, since the stimulation of HNE degradation restored the decline in cytochrome $c$ oxidase activity [53], HNE should inhibit cytochrome $c$ oxidase activity through the formation of HNE adducts with cytochrome $c$ oxidase subunits. These findings indicate that the protection of mitochondrial function, especially with regard to the cytochrome $c$ oxidase activity, could be important to prevent sarcopenia. As ALDH2 activity is suppressed in ALDH2*2 Tg mice, they cannot efficiently degrade HNE in muscles [8]. In this study, the consumption of a CSD maintained cytochrome $c$ oxidase activity in the gastrocnemius muscle of ALDH2*2 Tg mice, and a negative correlation between cytochrome $c$ oxidase activity and MDA and HAE was identified. Therefore, the consumption of Chlorella may act to prevent the accumulation of HNE, thereby preventing mitochondrial dysfunction through the protection of cytochrome $c$ oxidase activity.

As a lack of protein intake and decreased amino acid muscle protein synthesis leads to a decline in muscle mass, the intake of dietary protein has been recommended to slow and prevent the progression of sarcopenia $[54,55]$. With a protein content of approximately $65 \%$, the continuous intake of Chlorella may therefore be useful in both enhancing muscle protein synthesis and preventing muscle atrophy. In particular, Chlorella 
contains essential amino acids such as the BCAA valine, leucine, and isoleucine, which are important components of actin and myosin-composing muscle, and may be beneficial in the prevention and treatment of sarcopenia $[56,57]$.

Since Chlorella supplement contains various useful substances, it may not be easy to identify a single substance that exhibits a beneficial effect against muscle atrophy. Supplements with multiple compounds, such as Chlorella, may be particularly beneficial because of their synergic effects.

Finally, the present study showed the usefulness of this ALDH2 deficient mouse for evaluating anti-oxidative supplements.

\section{Conclusions}

This study demonstrates that long-term consumption of Chlorella in the diet has beneficial effects on body weight, and prevents oxidative stress, muscle atrophy, and mitochondrial dysfunction in ALDH2 $2 \mathrm{Tg}$ mice. This suggests that Chlorella intake may be useful in the treatment of sarcopenia.

\section{Abbreviations}

ALDH2: Aldehyde dehydrogenase 2; 4-HNE: 4-hydroxy-2-nonenal; Tg: Transgenic; ALDH2*2: Dominant-negative form of ALDH2; $\mathrm{ALDH}_{2}^{*} 2 \mathrm{Tg}$ mice: Muscle-specific mitochondrial ALDH2 activity deficient mice; CSD: Chlorella-supplemented diet; CPK: Creatine phosphokinase; ROS: Reactive oxygen species; MDA: Malondialdehyde; HAE: 4-hydroxyalkenals; HE: Hematoxylin and eosin; mtDNA: Mitochondrial DNA.

\section{Competing interests}

We declare that Y. Nakashima, S. Kumamoto, and I. Maruyama are employees of Chlorella Industry Co. Ltd. I. Ohsawa, K. Nishimaki, Y. Suzuki, and S. Ohta declare that they have no competing interests.

\section{Authors' contributions}

YN analyzed date, and drafted the manuscript. KN measured and analyzed the bone density. IO, KN, SK, IM, YS, and SO conducted the research and helped to draft the manuscript. All authors read and approved the final manuscript.

\section{Acknowledgements}

This research was supported by Chlorella Industry Co. Ltd.

\section{Author details}

'Department of Research and Development, Chlorella Industry Co. Ltd, 1343 Hisatomi, Chikugo, Fukuoka 833-0056, Japan. ${ }^{2}$ Department of Biochemistry and Cell Biology, Institute of Development and Aging Sciences, Nippon Medical School, 1-396 Kosugi-machi, Nakahara-ku, Kawasaki, Kanagawa 211-8533, Japan. ${ }^{3}$ Biological Process of Aging, Tokyo Metropolitan Institute of Gerontology, 35-2 Sakae, Itabashi-ku, Tokyo 173-0015, Japan.

Received: 23 May 2014 Accepted: 7 October 2014

Published: 11 October 2014

\section{References}

1. Mecocci P, Fanó G, Fulle S, MacGarvey U, Shinobu L, Polidori MC, Cherubini A, Vecchiet J, Senin U, Beal MF: Age-dependent increases in oxidative damage to DNA, lipids, and proteins in human skeletal muscle. Free Radic Biol Med 1999, 26:303-308.

2. Pansarasa O, Bertorelli L, Vecchiet J, Felzani G, Marzatico F: Age-dependent changes of antioxidant activities and markers of free radical damage in human skeletal muscle. Free Radic Biol Med 1999, 27:617-622.
3. Lim PS, Cheng YM, Wei YH: Increase in oxidative damage to lipids and proteins in skeletal muscle of uremic patients. Free Radic Biol Med 2002, 36:295-301.

4. Gianni P, Jan KJ, Douglas MJ, Stuart PM, Tarnopolsky MA: Oxidative stress and the mitochondrial theory of aging in human skeletal muscle. Exp Gerontol 2004, 39:1391-1400.

5. Hamilton ML, van Remmen H, Drake JA, Yang H, Guo ZM, Kewitt K, Walter CA, Richardson A: Does oxidative damage to DNA increase with age? Proc Natl Acad Sci U S A 2001, 98:10469-10474.

6. Çakatay U, Telci A, Kayali R, Tekeli F, Akçay T, Sivas A: Relation of aging with oxidative protein damage parameters in the rat skeletal muscle. Clin Biochem 2003, 36:51-55.

7. Ohsawa I, Nishimaki K, Murakami Y, Suzuki Y, Ishikawa M, Ohta S: Agedependent neurodegeneration accompanying memory loss in transgenic mice defective in mitochondrial aldehyde dehydrogenase 2 activity. J Neurosci 2008, 28:6239-6249.

8. Endo J, Sano M, Katayama T, Hishiki T, Shinmura K, Morizane S, Matsuhashi T, Katsumata Y, Zhang Y, Ito H, Nagahata Y, Marchitti S, Nishimaki K, Wolf AM, Nakanishi H, Hattori F, Vasiliou V, Adachi T, Ohsawa I, Taguchi R, Hirabayashi Y, Ohta S, Suematsu M, Ogawa S, Fukuda K: Metabolic remodeling induced by mitochondrial aldehyde stress stimulates tolerance to oxidative stress in the heart. Circ Res 2009, 105:1118-1127.

9. Conklin D, Prough R, Bhatanagar A: Aldehyde metabolism in the cardiovascular system. Mol Biosyst 2007, 3:136-150.

10. Higuchi S, Matsushita S, Masaki T, Yokoyama A, Kimura M, Suzuki G, Mochizuki $\mathrm{H}$ : Influence of genetic variations of ethanolmetabolizing enzymes on phenotypes of alcohol-related disorders. Ann NY Acad Sci 2004, 1025:472-480

11. Ohsawa I, Kamino K, Nagasaka K, Ando F, Niino N, Shimokata H, Ohta S: Genetic deficiency of a mitochondrial aldehyde dehydrogenase increases serum lipid peroxides in community-dwelling females. $J$ Hum Genet 2003, 48:404-409.

12. Kamino K, Nagasaka K, Imagawa M, Yamamoto H, Yoneda H, Ueki A, Kitamura S, Namekata K, Miki T, Ohta S: Deficiency in mitochondrial aldehyde dehydrogenase increases the risk for late-onset Alzheimer's disease in the Japanese population. Biochem Biophys Res Commun 2000, 273:192-196.

13. Suzuki $Y$, Muramatsu T, Taniyama M, Atsumi $Y$, Suematsu M, Kawaguchi $R$, Higuchi S, Asahina T, Murata C, Handa M, Mastuoka K: Mitochondrial aldehyde dehydrogenase in diabetes associated with mitochondrial tRNA(Leu(UUR)) mutation at position 3243. Diabetes Care 1996, 19:1423-1425.

14. Yokoyama A, Muramatsu T, Ohmori T, Yokoyama T, Okuyama K, Takahashi H, Hasegawa Y, Higuchi S, Maruyama K, Shirakura K, Ishii H: Alcohol-related cancers and aldehyde dehydrogenase- 2 in Japanese alcoholics. Carcinogenesis 1998, 19:1383-1387.

15. Takagi S, Baba S, Iwai N, Fukuda M, Katsuya T, Higaki J, Mannami T, Ogata J, Goto Y, Ogihara T: The aldehyde dehydrogenase 2 gene is a risk factor for hypertension in Japanese but does not alter the sensitivity to pressor effects of alcohol: the Suita study. Hypertens Res 2001, 24:365-370.

16. Chen CH, Ferreira JC, Gross ER, Mochly-Rosen D: Targeting aldehyde dehydrogenase2: new therapeutic opportunities. Physiol Rev 2014, 94:1-34.

17. Ohsawa I, Nishimaki K, Yasuda C, Kamino K, Ohta S: Deficiency in a mitochondrial aldehyde dehydrogenase increases vulnerability to oxidative stress in PC12 cells. J Neurochem 2003, 84:1110-1117.

18. Ohta S, Ohsawa I, Kamino K, Ando F, Shimokata H: Mitochondrial ALDH2 deficiency as an oxidative stress. Ann NY Acad Sci 2004, 1011:36-44.

19. Rosenberg $\mid \mathrm{H}$ : Sarcopenia: origins and clinical relevance. J Nutr 1997, 127:990S-991S

20. Janssen I, Shepard DS, Katzmarzyk PT, Roubenoff R: The healthcare costs of sarcopenia in the United States. J Am Geriatr Soc 2004, 52:80-85.

21. Baumgartner RN, Koehler KM, Gallagher D, Romero L, Heymsfield SB, Ross RR, Garry PJ, Lindeman RD: Epidemiology of sarcopenia among the elderly in New Mexico. Am J Epidemiol 2004, 147:755-763.

22. Melton LJ III, Khosla S, Crowson CS, O'Connor MK, O'Fallon WM, Riggs BL Epidemiology of sarcopenia. J Am Geriatr Soc 2000, 48:625-630.

23. Weindruch $\mathrm{R}$ : Interventions based on the possibility that oxidative stress contributes to sarcopenia. J Gerontol A Biol Sci Med Sci 1995, 50:157-161.

24. Schneider C, Tallman KA, Porter NA, Brash AR: Two distinct pathways of formation of 4-hydroxynonenal. Mechanisms of nonenzymatic transformation of the 9- and 13-hydroperoxides of linoleic acid to 4-hydroxyalkenals. J Biol Chem 2001, 276:20831-20838. 
25. Uchida K: 4-Hydroxy-2-nonenal: a product and mediator of oxidative stress. Prog Lipid Res 2003, 42:318-343.

26. Hasegawa T, Kimura Y, Hiromastsu K, Kobayashi N, Yamada A, Makino M, Okuda M, Sano T, Nomoto K, Yoshikai Y: Effect of hot water extract of Chlorella vulgaris on cytokine expression patterns in mice with murine acquired immunodeficiency syndrome after infection with Listeria monocyto-genes. Immunopharmacology 1997, 35:273-282.

27. Konishi F, Tanaka K, Himeno K, Taniquti K, Nomoto K: Antitumor effect induced by a hot water extract of Chlorella vulgaris (CE): resistance to Meth-A tumor growth mediated by CE-induced polymorphonuclear leukocytes. Cancer Immunol Immunother 1985, 19:73-78.

28. Tanaka K, Koga T, Konishi F, Nakamura M, Mitsuyama M, Himeno K, Nomoto $\mathrm{K}$ : Augmentation of host defense by a unicellular green alga, Chlorella vulgaris, to Escherichia coli infection. Infect Immun 1986, 53:267-271.

29. Lee HS, Choi CY, Cho C, Song Y: Attenuating effect of chlorella supplementation on oxidative stress and NFkappaB activation in peritoneal macrophages and liver of $\mathrm{C} 57 \mathrm{BL} / 6$ mice fed on an atherogenic diet. Biosci Biotechnol Biochem 2003, 67:2083-2090.

30. Pratt R, Johnson E: Production of thiamine, riboflavin, folic acid, and biotin by Chlorella vulgaris and Chlorella pyrenoidosa. J Pharm Sci 1965, 54:871-874.

31. Shibata S, Natori Y, Nishihara T, Tomisaka K, Matsumoto K, Sansawa H, Nguyen VC: Antioxidant and anti-cataract effects of chlorella on rats with streptozotocin induced diabetes. J Nutr Sci Vitaminol (Tokyo) 2003, 49:334-339.

32. Makpol S, Yeoh TW, Ruslam FA, Arifin KT, Yusof YA: Comparative effect of Piper betle, Chlorella vulgaris and tocotrienol-rich fraction on antioxidant enzymes activity in cellular ageing of human diploid fibroblasts. BMC Complement Altern Med 2013, 13(1):1-10

33. Aizzat O, Yap SW, Sopiah H, Madiha MM, Hazreen M, Shailah A, Wan JW, Nur SA, Srijit D, Musalmah M, Yasmin AM: Modulation of oxidative stress by Chlorella vulgaris in streptozotocin (STZ) induced diabetic SpragueDawley rats. Adv Med Sci 2010, 55(2):281-288.

34. Aliahmat NS, Noor MR, Yusof WJ, Makpol S, Ngah WZ, Yusof YA Antioxidant enzyme activity and malondialdehyde levels can be modulated by Piper betle, tocotrienol rich fraction and Chlorella vulgaris in aging C57BL/6 mice. Clinics (Sao Paulo) 2012, 67(12):1147-1154.

35. Peng HY, Chu YC, Chen SJ, Chou ST: Hepatoprotection of chlorella against carbon tetrachloride-induced oxidative damage in rats. In Vivo 2009, 23(5):747-754

36. Son YA, Shim JA, Hong S, Kim MK: Intake of Chlorella vulgaris improves antioxidative capacity in rats oxidatively stressed with dietary cadmium. Ann Nutr Metab 2009, 54(1):7-14.

37. Vijayavel K, Anbuselvam C, Balasubramanian MP: Antioxidant effect of the marine algae Chlorella vulgaris against naphthalene-induced oxidative stress in the albino rats. Mol Cell Biochem 2007, 303(1-2):39-44.

38. Kawasaki H, Sano T, Kaku E, Watanabe K, Kumamoto Y, Tanaka K: Toxicological study of chlorella. Acute and subacute toxicity in young rats by oral administration (in Japanese). Kurumeigakukaizasshi 1977, 40(11):1510-1516.

39. Nakashima Y, Ohsawa I, Konishi F, Hasegawa T, Kumamoto S, Suzuki Y, Ohta S: Preventive effects of Chlorella on cognitive decline in age-dependent dementia model mice. Neurosci Lett 2009, 464:193-198.

40. Hasegawa T, Ito K, Ueno S, Kumamoto S, Ando Y, Yamada A, Nomoto K, Yasunobu Y: Oral administration of hot water extracts of Chlorella vulgaris reduces IgE production against milk casein in mice. Int J Immunopharmacol 1999, 21(5):311-323.

41. Reeves PG, Nielsen FH, Fahey GC: AIN-93 purified diets for laboratory rodents: final report of the American Institute of Nutrition $\mathrm{Ad} \mathrm{Hoc}$ Writing Committee on the Reformulation of the AIN-76A Rodent Diet. J Nutr 1993, 123:1939-1951.

42. McKenzie D, Bua E, McKiernan S, Cao Z, Aiken JM: Mitochondrial DNA deletion mutations: a causal role in sarcopenia. Eur J Biochem 2002, 269:2010-2015.

43. Semba RD, Lauretani F, Ferrucci L: Carotenoids as protection against sarcopenia in older adults. Arch Biochem Biophys 2007, 458:141-145.

44. Kruk J, Jemioła-Rzemińska M, Strzałka K: Plastoquinol and $a$-tocopherol quinol are more active than ubiquinol and $a$-tocopherol in inhibition of lipid peroxidation. Chem Phys Lipids 1997, 87:73-80.

45. Skulachev VP, Anisimov VN, Antonenko YN, Bakeeva LE, Chernyak BV, Erichev VP, Filenko OF, Kalinina NI, Kapelko VI, Kolosova NG, Kopnin BP,
Korshunova GA, Lichinitser MR, Obukhova LA, Pasyukova EG, Pisarenko OI, Roginsky VA, Ruuge EK, Senin II, Severina II, Skulachev MV, Spivak IM, Tashlitsky VN, Tkachuk VA, Vyssokikh MY, Yaguzhinsky LS, Zorov DB: An attempt to prevent senescence: a mitochondrial approach. Biochim Biophys Acta 2009, 1787:437-461.

46. Hiona A, Leeuwenburgh C: The role of mitochondrial DNA mutations in aging and sarcopenia: implications for the mitochondrial vicious cycle theory of aging. Exp Gerontol 2008, 43:24-33.

47. Wanagat J, Cao Z, Pathare P, Aiken JM: Mitochondrial DNA deletion mutations colocalize with segmental electron transport system abnormalities, muscle fiber atrophy, fiber splitting, and oxidative damage in sarcopenia. Faseb J 2001, 15:322-332.

48. Cao Z, Wanagat J, McKiernan SH, Aiken JM: Mitochondrial DNA deletion mutations are concomitant with ragged red regions of individual, aged muscle fibers: analysis by laser-capture microdissection. Nucleic Acids Res 2001, 29:4502-4508.

49. Bua EA, McKiernan SH, Wanagat J, McKenzie D, Aiken JM: Mitochondrial abnormalities are more frequent in muscles undergoing sarcopenia. J Appl Physiol 2002, 92:2617-2624

50. Gokey NG, Cao Z, Pak JW, Lee D, McKiernan SH, McKenzie D, Weindruch R, Aiken JM: Molecular analyses of mtDNA deletion mutations in microdissected skeletal muscle fibers from aged rhesus monkeys. Aging Cell 2004, 3:319-326.

51. Bua E, Johnson J, Herbst A, Delong B, McKenzie D, Salamat S, Aiken JM: Mitochondrial DNA-deletion mutations accumulate intracellularly to detrimental levels in aged human skeletal muscle fibers. Am J Hum Genet 2006, 79:469-480.

52. Herbst A, Pak JW, McKenzie D, Bua E, Bassiouni M, Aiken JM: Accumulation of mitochondrial DNA deletion mutations in aged muscle fibers: evidence for a causal role in muscle fiber loss. $J$ Gerontol A Biol Sci Med Sci 2007, 62:235-245.

53. Chen J, Schenker S, Frosto TA, Henderson GI: Inhibition of cytochrome c oxidase activity by 4-hydroxynonenal (HNE). Role of HNE adduct formation with the enzyme subunits. Biochim Biophys Acta 1998, 1380:336-344.

54. Paddon-Jones D, Short KR, Campbell WW, Volpi E, Wolfe RR: Role of dietary protein in the sarcopenia of aging. Am J Clin Nutr 2008, 87:1562S-1566S.

55. Paddon-Jones D, Rasmussen BB: Dietary protein recommendations and the prevention of sarcopenia. Curr Opin Clin Nutr Care 2009, 12:86-90.

56. Dreyer HC, Volpi E: Role of protein and amino acids in the pathophysiology and treatment of sarcopenia. J Am Coll Nutr 2005, 24:140S-145S.

57. Fujita S, Volpi E: Amino acids and muscle loss with aging. J Nutr 2006, 136:277S-280S.

doi:10.1186/1472-6882-14-390

Cite this article as: Nakashima et al:: Preventive effects of Chlorella on skeletal muscle atrophy in muscle-specific mitochondrial aldehyde dehydrogenase 2 activity-deficient mice. BMC Complementary and Alternative Medicine 2014 14:390.

\section{Submit your next manuscript to BioMed Central and take full advantage of:}

- Convenient online submission

- Thorough peer review

- No space constraints or color figure charges

- Immediate publication on acceptance

- Inclusion in PubMed, CAS, Scopus and Google Scholar

- Research which is freely available for redistribution 